\title{
Geometrical Evaluation of Cervical Cells. Fractal and Euclidean Diagnostic Methodology of Clinical Application
}

\author{
Javier Rodríguez Velásquez ${ }^{1 *}$, Miguel Sánchez Cárdenas ${ }^{2}$, \\ Freddy Andrés Barrios Arroyave ${ }^{1,3,4,5}$, Yolanda Soracipa Muñoz ${ }^{1}$ \\ ${ }^{1}$ Insight Group, Research Center of the Clínica del Country, Bogota, Colombia \\ ${ }^{2}$ Research and Social Projection. the Health, Sexual and Reproductive Research Group, Universidad el Bosque, Bogota, Colombia \\ ${ }^{3}$ Sexual and Reproductive Health, Universidad el Bosque Bogota, Colombia \\ ${ }^{4}$ Epidemiology and Biostatistics, CES University, Medellin, Colombia \\ ${ }^{5}$ Epidemiology and Biostatistics Research Group, CES University and GISCO (Health and Community Research Group) \\ Fundación Universitaria Autónoma de las Américas, Pereira, Colombia \\ Email: ^grupoinsight2025@yahoo.es, sanchezcmiguel@unbosque.edu.co, barrios.freddy@uces.edu.co, \\ pregrupoinsight@gmail.com
}

How to cite this paper: Velásquez, J.R., Cárdenas, M.S., Arroyave, F.A.B. and Muñoz, Y.S. (2018) Geometrical Evaluation of Cervical Cells. Fractal and Euclidean Diagnostic Methodology of Clinical Application. Journal of Biosciences and Medicines, 6, 111-122. https://doi.org/10.4236/jbm.2018.63009

Received: January 14, 2018

Accepted: March 17, 2018

Published: March 20, 2018

Copyright $\odot 2018$ by authors and Scientific Research Publishing Inc. This work is licensed under the Creative Commons Attribution International License (CC BY 4.0).

http://creativecommons.org/licenses/by/4.0/

(c) $\underset{\mathrm{EY}}{\mathrm{C}}$ Open Access

\begin{abstract}
Background: The concomitant use of fractal and Euclidian measurements has led to the development of new methodologies of cell evaluation, including a diagnosis of cervical cells that set up differences between normality and various degrees of lesion, to carcinoma. Aim: To confirm the diagnostic capacity of the methodology based on fractal and Euclidian geometry for the mathematical diagnosis through a blind study of normal cells and with different types of lesion, as atypia of undetermined significance (ASCUS), low grade squamous intra-epithelial lesion (LGSIL) and high grade squamous intra-epithelial lesion (HGSIL). Methods: 100 cells of Papanicolaou tests were analyzed and divided into 4 groups according to conventional parameters: 25 normal, 25 ASCUS, 25 LGSIL and 25 HGSIL. By means of the Box-counting Fractal Space, we calculated the fractal dimension and occupying spaces of the border and surface in pixels of the cell nucleus and cytoplasm. The diagnostic parameters of the previously developed methodology were applied and compared with the conventional diagnosis, setting up sensibility, specificity, negative likelihood ratio and Kappa coefficient. Results: The values of the occupation of the border and surface of the cell nucleus and cytoplasm were consistent with the values found by the diagnostic methodology previously found. The subtraction of the nucleus and cytoplasm frontiers presented values between: 189 and 482 for normality; 159 and 432 for ASCUS; 126 to 401 for LGSIL and 39 to 122 for HGSIL. A sensitivity and specificity of $100 \%$, and a
\end{abstract}


Kappa coefficient of 1 were obtained. Conclusions: The capacity of the methodology to diagnose quantitatively the different stages in the evolution of the cervical cells observed in Papanicolaou tests was confirmed, from normality to HGSIL.

\section{Keywords}

Fractals, Cervical Cancer, Cytology, Mathematics

\section{Introduction}

The cervical cancer occupies the sixth place among the most frequent types of cancer in women worldwide, while it is the twelfth most frequent at a general level [1]. In 2008, about 290,000 new cases of cervical cancer were detected. This pathology was responsible of near $5 \%$ of all the new cases of cancer in women. Though there are vaccines available against the papilloma virus $(\mathrm{PVH})$ that prevents infections for the serotypes 16 and 18 , which presumably are responsible for about $70 \%$ to $75 \%$ of all cervical cancers [2] [3], some strategies as massive vaccination against $\mathrm{PVH}$ implemented by the countries with a higher incidence have not achieved the expected success, due to their high costs [4] [5] [6]. For this reason, the cervicovaginal cytology (CVC) continues to be the most used test for the early detection of cervicouterine cancer [7].

Following up the evaluation of the CVC makes possible the detection of cells with lesions that indicate the development of the disease. However, there is not a worldwide consensus for this evaluation; also, it has been shown that there are inter and intra observer reproducibility problems, since that evaluation is based on qualitative operator-dependent observations. Reproducibility problems are also evidenced in the simultaneous observation of several qualitative parameters including the size of the nucleus and the cytoplasm [8] [9] [10] [11].

Some studies that apply fractal methodologies to the study of neoplastic structures have been developed, and some analyses of mammograms [12] [13], to the cells of the oral mucosa [14], in bladder invasive cancer [15], and in ocular tissue [16], among others [17] [18] [19], have also been applied. Recently, applications of fractal geometry to the analysis of the nucleus and cytoplasm of cervical cells have been developed [20] [21], which permit to differentiate normality of Low Grade Squamous Intraepithelial Lesions (LGSIL) and High Grade Squamous Intraepithelial Lesions (HGSIL), determining, moreover, mathematical relations of the ASCUS cells (Squamous Atypia of Undetermined Significance) which associate them to an state of normality or lesion. These works gave origin to a diagnosis that simultaneously applies fractal and Euclidian measurements to the border and surface of the nucleus and cytoplasm in the generalized fractal space of Box Counting, which, in addition to providing an objective and reproducible diagnosis of these states, establishes some values associated to the 
evolution between LGSIL and HGSIL [22]. Afterwards, a generalization was carried out, through which all possible clinically observable cell evolution paths from normality to cancer were established, providing an objective and reproducible evaluation of normality and lesion, as well as the evolution of these two states [23].

\section{Materials and Methods}

Definitions.

- Boundary of the object: When superimposing the grid of 2 pixels next to the defined objects (cytoplasm and nucleus), the number of squares which occupy the contours of the objects will be named the boundary of the object.

- Surface of the object: Number of pixels occupying the interior of each of the measured objects (cytoplasm and nucleus).

- Difference between boundaries: Subtraction between the boundaries of the cytoplasm and nucleus.

- Fractal: derived from Latin fractus, meaning broken or fractured.

- Fractal dimension: measure used to evaluate the irregularity of an object. For the wild fractals the Box-counting fractal dimension is usually used.

- Box-counting fractal dimension: See Equation (A1) [20], let $N$ the number of squares occupied by the object measured with the partition grid $K$, and $D$ the fractal dimension. For the measurements developed in the present work we used two grids of 2 and 4 side pixels.

$$
D=\log _{2} \frac{N\left(2^{-(K+1)}\right)}{N\left(2^{-K}\right)}
$$

Procedure. Within the database of the Insight group, 100 cells were selected, obtained from Papanicolaou samples of cervical squamous epithelium; they were split into four groups according to the conventional clinical evaluation provided by an expert pathologist: 25 LGSIL, 25 HGSIL, 25 ASCUS, and 25 normal. The cytology samples of cervical squamous epithelium selected for the study came from patients whose ages ranged from 20 and 53 year old. The diagnoses established through the conventional method were masked, and those of the cytology samples extended on plate were photographed with a zoom of $100 \times$. A representative cell of each sample was selected. Afterwards, the photographs of the cells were taken to an image editor.

Two geometrical objects were defined: cytoplasm and nucleus, and using previously defined software, their boundaries with the grid of 2 pixels of side and their surfaces with the number of pixels were measured (see definitions). The fractal dimension of Box-counting of the boundaries of the objects was also calculated, using two grids of 2 and 4 pixels of side, then the subtraction between the values of the border of the nucleus and cytoplasm was also calculated. Once these measurements were found, they were analyzed with the mathematical parameters of diagnosis support of the previously developed methodology [23], where the values greater than or equal to 161 in the subtraction of the 
cytoplasm-nucleus borders and nuclear surfaces less than or equal to 735 were associated to normality; values greater than 130 in the subtraction of the cytoplasm-nucleus border and nuclear surfaces greater than or equal to 972 were associated to LGSIL; while the HGSIL cells showed values lower than 120 in the subtraction of the cytoplasm-nucleus border. Values among 120 - 130 in the subtraction of the cytoplasm-nucleus border corresponded to the evolution between LGSIL and HGSIL.

Statistical analysis. The cytopathological diagnoses of the samples were unmasked, which were taken as the Gold-standard, in order to develop the statistical analysis. The value of the True Positives (TP) was estimated, corresponding to the cells which both for the evaluation with the mathematical methodology, and for the conventional diagnosis, were evaluated as sick people, the true negatives (TN) corresponding to the cells mathematically evaluated as normal, and equally with the conventional diagnosis, the false positives (FP) corresponding to the number of cells which are histologically diagnosed as normal, but mathematically as sick, and the false negatives (FN), which is the number of cells mathematically evaluated as normal but with a histological diagnosis of lesion. With these values, the sensibility and specificity, as well as the kappa coefficient were found. The cells classified as ASCUS, for not having a specific histological diagnosis of lesion or normality, were excluded from statistical analysis.

\section{Results}

The nucleus surface, measured in pixels, showed quantities between the following values: 301 to 714 for normality; 1277 to 4694 for ASCUS; 979 to 5431 for LGSIL and 573 to 2680 for HGSIL.

The nucleus frontier, evaluated in the grid of 2 pixel's side showed values among 37 to 55 for normal cells; between 74 and 134 for ASCUS; between 71 and 158 for LGSIL and between 65 and 188 for HGSIL.

The subtraction of the nucleus and cytoplasm frontiers presented values between: 189 and 482 for normality; 159 and 432 for ASCUS; 126 to 401 for LGSIL and 39 to 122 for HGSIL.

The fractal dimensions of the objects showed that these values cannot differentiate any state, confirming previous results.

When establishing the physical-mathematical diagnosis according to the results of Rodriguez et al [23], it was found that the diagnosis made by the pathologist for normal cells, LGSIL and HGSIL coincided with the mathematical diagnosis in all cases. Some examples of the values founded for each state can be seen at Tables 1-3.

Furthermore, cells conventionally diagnosed as ASCUS presented values of normal, LGSIL or evolution between LGSIL and HGSIL, which is consistent with previous findings. Examples of ASCUS mathematical diagnosis are shown at Table 4, where the cell No. 2 had values corresponding to normality; cells 1, 3, 4 and 5 had values corresponding to LGSIL, and cells 6 and 7 had values of evolution 
Table 1. Measures of seven of the normal cells evaluated.

\begin{tabular}{ccccc}
\hline \multicolumn{6}{l}{ Cell No. Nucleus Surface Nucleus Frontier Citoplasm Frontier } & $\begin{array}{c}\text { Subtraction of } \\
\text { Cytoplasm-Nucleus Frontiers }\end{array}$ \\
\hline 1 & 378 & 40 & 361 & 321 \\
2 & 644 & 37 & 226 & 189 \\
3 & 510 & 46 & 398 & 352 \\
4 & 505 & 55 & 531 & 476 \\
5 & 714 & 41 & 490 & 449 \\
6 & 483 & 48 & 530 & 482 \\
7 & 301 & 52 & 287 & 235 \\
\hline
\end{tabular}

Table 2. Measures of seven of the LGSIL cells evaluated.

\begin{tabular}{ccccc}
\hline \multicolumn{6}{c}{ Cell No. Nucleus Surface Nucleus Frontier Citoplasm Frontier } & $\begin{array}{c}\text { Subtraction of } \\
\text { Cytoplasm-Nucleus Frontiers }\end{array}$ \\
\hline 1 & 4601 & 158 & 461 & 303 \\
2 & 2748 & 105 & 237 & 342 \\
3 & 5431 & 135 & 340 & 205 \\
4 & 1036 & 71 & 388 & 317 \\
5 & 994 & 74 & 210 & 136 \\
6 & 5377 & 141 & 521 & 380 \\
7 & 979 & 110 & 511 & 401 \\
\hline
\end{tabular}

Table 3. Measures of seven of the HGSIL cells evaluated.

\begin{tabular}{ccccc}
\hline Cell No. Nucleus Surface Nucleus Frontier Citoplasm Frontier & $\begin{array}{c}\text { Subtraction of } \\
\text { Cytoplasm-Nucleus Frontiers }\end{array}$ \\
\hline 1 & 573 & 70 & 182 & 112 \\
2 & 1658 & 111 & 155 & 44 \\
3 & 599 & 65 & 153 & 88 \\
4 & 2680 & 138 & 190 & 52 \\
5 & 2203 & 249 & 203 & 46 \\
6 & 1371 & 98 & 137 & 39 \\
7 & 2592 & 170 & 99 & 71 \\
\hline
\end{tabular}

Table 4. Measures of seven of the ASCUS cells evaluated.

\begin{tabular}{ccccc}
\hline \multicolumn{2}{l}{ Cell No. Nucleus Surface Nucleus Frontier Citoplasm Frontier } & $\begin{array}{c}\text { Subtraction of } \\
\text { Cytoplasm-Nucleus Frontiers }\end{array}$ \\
\hline 1 & 1395 & 134 & 495 & 361 \\
2 & 707 & 87 & 394 & 307 \\
3 & 4031 & 89 & 521 & 432 \\
4 & 3504 & 166 & 528 & 362 \\
5 & 2749 & 76 & 238 & 162 \\
6 & 689 & 79 & 209 & 130 \\
7 & 652 & 121 & 245 & 124 \\
\hline
\end{tabular}


Table 5. Minimum (MN) and maximum (MX) fractal dimensions found in each group for the measured objects.

\begin{tabular}{ccccc}
\hline Diagnosis & & Nucleus Measurement & Cytoplasm Measurement & Total Cell Measurement \\
\hline \multirow{2}{*}{ NORMAL } & MN & 1.147 & 0.854 & 1.095 \\
& $\mathrm{MX}$ & 1.257 & 1.152 & 1.069 \\
& $\mathrm{MN}$ & 1.109 & 1.219 & 1.135 \\
ASCUS & $\mathrm{MX}$ & 0.874 & 1.223 & 1.284 \\
& $\mathrm{MN}$ & 1.052 & 1.1 & 0.916 \\
\multirow{2}{*}{ LGSIL } & $\mathrm{MX}$ & 1.065 & 0.87 & 1.113 \\
& $\mathrm{M}$ & 1.044 & 1.206 & 0.806 \\
HGSIL & $\mathrm{MN}$ & 1.291 & 1.29 & 1.308 \\
& $\mathrm{MX}$ & & & \\
\hline
\end{tabular}

between LGSIL and HGSIL.

Finally, Minimum (MN) and maximum (MX) fractal dimensions found in each group for the measured objects are presented in Table 5.

About statistical analysis, it was found that it was obtained a sensitivity and specificity of $100 \%$; the negative likelihood ratio was zero, and Kappa coefficient was one.

\section{Discussion}

This work applies a mathematical diagnostic methodology based on fractal and euclidian geometry to 100 normal cells of the squamous cervical epithelium with diverse degrees of lesion, confirming the diagnostic capacity of the method through a blind study. The results evidenced that the measurements permit to determine objectively and reproductively the state of normality or of lesion, as well as the degree of evolution of the disorder. The significance of this study is that these findings allow using the method as a useful diagnostic tool at clinical level, overcoming the difficulties of reproducibility of the conventional methods of classification, such as the Bethesda system.

The developed measurements allow the differentiation between the ASCUS cells with lesion patterns or with patterns of normality, providing a useful objective diagnosis in decision making at clinical level, overcoming the difficulties posed by the ASCUS conventional diagnosis, to the extent that this diagnosis does not clearly show a state of normality or lesion.

Some previous studies have evidenced that though the specificity of the CVC is of $98 \%$, its sensibility is around $51 \%$ [8]. On the other hand, the present study established values of sensibility and specificity of $100 \%$ for the mathematical test, a negative likelihood ration of zero, and a Kappa coefficient of one, evidencing the capacity of the fractal and Euclidian geometry used simultaneously to set up objective measurements of the state of normality or of lesion of the cell structure, independently from the analysis of the population or statistical type.

Previous studies had already made use of the fractal geometry to set up dif- 
ferences between states of normality and cancer in different structures [12] [13] [14] [15]. For example, when a multifractal analysis of the connective tissue of interphase of the oral mucosa was carried out in different degrees of neoplasia lesion, spectrums of values for their discrimination were found, study carried out by Landini and Rippin [14]. Likewise, several findings have been identified in the field of statistical analysis of digital mammograms [12] [13]. Luzi et al. [15] analyzed, using statistical methods, the fractal dimensions of samples of bladder invasive cancer, resulting in the decrease of the fractal dimension with respect to the histological degree of lesion, what has been useful for the identification of the risk of cancer.

However, diverse research works have evidenced that the fractal dimensions analyzed in isolation not always lead to differential diagnostic information [24] [25] [26] [27], which has created the need for the development of mathematical concepts for the analysis. In the case of cervical cancer, the concepts of Cell Intrinsic Mathematical Harmony, and Variability of the Fractal Dimension were developed, which permitted the establishment of differences between normality and HGSIL, from fractal measurements of the nucleus, cytoplasm, and the whole cell [27] [28].

There was a recent development of a new method of evaluation of the erythrocyte structure based on fractal and Euclidian geometry simultaneously [29], and this led to the establishment of objective measurements of the border and surface of the cell structure, while considering its irregularity when applying these measurements in the generalized space of Box Counting. This innovation was used in the analysis of cervical cells, evidencing that values greater than the border of the nucleus are associated with states of greater gravity at histological level, allowing for a quantification of all the process of evolution from normality to cancer [30]. This finding constitutes the fundamentals of the diagnostic methodology evaluated in the present study [27], whose diagnostic applicability was confirmed. This method was also the basis for the development of a generalization through which all the possible paths of geometrical alteration of the cervical cells are established, from normality to HGSIL, constituting a useful method at diagnostic and preventive level [23].

The evaluation of the cell structure from the joint application of the fractal and Euclidian geometries makes possible the procurement of a better comprehension of the cell evolution phenomenon to carcinoma, since there is a geometrical generalization of the phenomenon in which the parts and the whole of the geometrical structure are determined, resulting in objective quantifying measurements of the state of normality or alteration for any particular cell of the cervix, without the need for epidemiological variables or statistical studies which account for population behaviors that sometimes are not applicable to each particular case [31].

Currently, it is not necessary to consider the causal determinism for the description of a phenomenon, since from modern physics, like statistical mechanics [32], and the chaos theory [33], causality has stopped being the ground for 
the understanding of nature. From Prigogine's chaotic-deterministic conception, it is decreed that the order of the studied phenomenon is found from temporal windows of the phenomenon. In this way, upon the analysis of the cervical cell evolution from geometrical and mathematical measurements in this work, only temporary windows of cell evolution are obtained which are deprived of any causal relation, but that may have a temporary correspondence from a geometrical and mathematical acausal order. Expecting causes-consequences in molecular cascades or the influence of epigenetic factors in the evolution of cancer are appreciations which are not taken into consideration in the fundamental conceptualization of the completed process.

From the perspective of this acausal view of nature, and from ways of reasoning based on mental experiments, applications of physical and mathematical theories to different fields of medicine have been developed. In the case of cardiology, for example, the theories of probability and entropy contributed to the development of a diagnostic methodology whose clinical application has been demonstrated [34], and a geometrical law for chaotic dynamic systems has been found [35]; in epidemiology, predictions on malaria outbreak in Colombian towns were made in a three-week period of time [36]; in infectology, it was possible to predict the population of T CD4 lymphocytes from information reported in the blood picture [37], which turned to be of great importance for VIH patients; in molecular biology, a union predictive theory was developed, based on combinatory, probability and entropy logics applied to monomeric peptides presented by the class II HLA (Human leukocyte antigen) [38]. Recently, a new methodology for the prediction of mortality in Intensive care unit was developed, based on the analysis of hemodynamic variables with dynamical systems and set theory [39].

\section{Ethical Aspects}

The present research complies with the ethical principles of the Helsinki Declaration of the World Medical Association. According to Resolution 008430 of 1993, of the Ministry of Health in Colombia, the research is classified as risk-free, since physical calculations are carried out over results of reports and non-invasive tests of the clinical practice which have been previously prescribed, protecting the integrity and anonymity of the participants.

\section{Ethical Approval}

All procedures performed in studies involving human participants were in accordance with the ethical standards of the institutional and national research committee and with the 1964 Helsinki declaration and its later amendments or comparable ethical standards. The participants signed the informed consent.

\section{Acknowledgements}

This paper makes part of the products developed in the PIC-2014-19 project, 
approved by the Research Division of the Universidad el Bosque, to which we extend our gratitude. Likewise, we thank Dr. Hector Posso, scientific director of the Liga Contra el Cancer, for his support to our research, as well as Dr. Catalina Correa and Dr. Signed Prieto, researchers of the Insight Group, for their help in the software management and data analysis.

Finally, we thank the Research Center of the Clínica del Country for the support to our research project, in particular to Doctors Tito Tulio Roa, Jorge Ospina, Alfonso Correa, Adriana Ortiz, Silvia Ortiz, chief nurse of the Research Center, and Sandra Rodriguez, as well as to Juan Camilo Benítez, bacteriologist of the Center.

\section{Conflicts of Interest Statement}

None declared.

\section{Funding}

Work prepared by the Research Division of the Universidad El Bosque, PIC-2014-19 project.

\section{References}

[1] GLOBOCAN (2008) Cancer Incidence and Mortality Worldwide: IARC Cancer Base No. 10. International Agency for Research on Cancer, Lyon, France. http://globocan.iarc.fr/old/FactSheets/cancers/cervix-new.asp

[2] Clifford, G., Franceschi, S. and Diaz, M. (2006) Chapter 3: HPV Type-Distribution in Women with and without Cervical Neoplastic Diseases. In: Clifford, G., Franceschi, S. and Diaz, M., Eds., Vaccine, E-Publishing Inc., New York, 26-34. https://doi.org/10.1016/j.vaccine.2006.05.026

[3] Muñoz, N., Bosch, F.X., Castellsagué, X., Díaz, M., de Sanjose, S., Hammouda, D., et al. (2004) Against Which Human Papillomavirus Types Shall We Vaccinate and Screen? The International Perspective. International Journal of Cancer, 111, 278-285. https://doi.org/10.1002/ijc.20244

[4] Goldie, S.J., O’Shea, M. and Campos, N.G. (2008) Health and Economic Outcomes of HPV 16, 18 Vaccination in 72 GAVI-Eligible Countries. Vaccine, 26, 4080-4093. https://doi.org/10.1016/j.vaccine.2008.04.053

[5] Andrus, J.K., Sherris, J. and Fitzsimmons, J.W. (2008) Introduction of Human Papillomavirus Vaccines into Developing Countries-International Strategies for Funding and Procurement. Vaccine, 26, K87-K92.

https://doi.org/10.1016/j.vaccine.2008.05.003

[6] Sankaranarayanan, R., Nene, B.M., Shastri, S.S., Jayant, K., Muwonge, R., Budukh, A.M., et al. (2009) HPV Screening for Cervical Cancer in Rural India. The New England Journal of Medicine, 360, 1385-1394. https://doi.org/10.1056/NEJMoa0808516

[7] Gakidou, E., Nordhagen, S. and Obermeyer, Z. (2008) Coverage of Cervical Cancer Screening in 57 Countries: Low Average Levels and Large Inequalities. PLoS Medicine, 5, e132. https://doi.org/10.1371/journal.pmed.0050132

[8] Adab, P., McGhee, S.M., Yanova, J., Wong, C.M. and Hedley, A.J. (2004) Effectiveness and Efficiency of Opportunistic Cervical Cancer Screening: Comparison with 
Organized Screening. Medical Care, 42, 600-609.

https://doi.org/10.1097/01.mlr.0000128007.04494.29

[9] Nanda, K., McCrory, D.C., Myers, E.R., Bastian, L.A., Hasselblad, V., Hickey, J.D., et al. (2000) Accuracy of the Papanicolaou Test in Screening for and Follow-Up of Cervical Cytologic Abnormalities: A Systematic Review. Annals of Internal Medicine, 132, 810-819. https://doi.org/10.7326/0003-4819-132-10-200005160-00009

[10] Schmidt, J.L., Henriksen, J.C., McKeon, D.M., Savik, K., Gulbahce, H.E. and Pambuccian, S.E. (2008) Visual Estimates of Nucleus-to-Nucleus Ratios: Can We Trust Our Eyes to Use the Bethesda ASCUS and LSIL Size Criteria? Cancer, 114, 287-293. https://doi.org/10.1002/cncr.23798

[11] Geisinger, K.R., Vrbin, C., Grzybicki, D.M., Wagner, P., Garvin, A.J. and Raab, S.S. (2007) Interobserver Variability in Human Papillomavirus Test Results in Cervico Vaginal Cytologic Specimens Interpreted as Atypical Squamous Cells. American Journal of Clinical Pathology, 128, 1010-1014.

https://doi.org/10.1309/J086T2UB1WDL1LQU

[12] Stępień, R. and Stępień, P. (2010) Analysis of Contours of Tumor Masses in Mammograms by Higuchi's Fractal Dimension. Biocybernetics and Biomedical Engineering, 30, 49-46.

[13] Sankar, D. and Thomas, T. (2010) A New Fast Fractal Modeling Approach for the Detection of Microcalcifications in Mammograms. Journal of Digital Imaging, 23, 538-546. https://doi.org/10.1007/s10278-009-9224-6

[14] Landini, G. and Rippin, J.W. (1993) Fractal Dimensions of Epithelial-Connective Tissue Interfaces in Premalignant and Malignant Epithelial Lesions of the Floor of Mouth. Analytical and Quantitative Cytology and Histology, 15, 144-149.

[15] Luzi, P., Bianciardi, G., Miracco, C., De Santi, M.M., Del Vecchio, M.T., Alia, L. and Tosi, P. (1999) Fractal Analysis in Human Pathology. Annals of the New York Academy of Sciences, 879, 255-257. https://doi.org/10.1111/j.1749-6632.1999.tb10428.x

[16] Gazit, Y., Berk, D.A., Lunig, M., Baxter, L.T. and Jain, R.K. (1995) Scale-Invariant Behavior and Vascular Network Formation in Normal and Tumor Tissue. Physical Review Letters, 75, 2428-2431. https://doi.org/10.1103/PhysRevLett.75.2428

[17] De Arruda, F.F., Gatti Facio, F.N., De Arruda, J.G.F., Moreira, R.D., Murta, L.O., De Arruda, L.F., et al. (2013) Quantification of Fractal Dimension and Shannon's Entropy in Histological Diagnosis of Prostate Cancer. BMC Clinical Pathology, 13, 6. https://doi.org/10.1186/1472-6890-13-6

[18] Klatt, J., Gerich, C.E., Gröbe, A., Opitz, J., Schreiber, J., Hanken, H., et al. (2014) Fractal Dimension of Time-Resolved Autofluorescence Discriminates Tumour from Healthy Tissues in the Oral Cavity. Journal of Cranio-Maxillo-Facial Surgery, 42, 852-854. https://doi.org/10.1016/j.jcms.2013.12.004

[19] Metze, K. (2013) Fractal Dimension of Chromatin: Potential Molecular Diagnostic Applications for Cancer Prognosis. Expert Review of Molecular Diagnostics, 13, 719-735. https://doi.org/10.1586/14737159.2013.828889

[20] Rodríguez, J. (2011) New Fractal Method of Diagnostic aid for Preneoplastic Cells of the Cervical Squamous Epithelium. Revista UDCA Actualidad \& Divulgación Científica, 14, 15-22.

[21] Rodríguez, J., Prieto, S., Correa, C., Posso, H., Bernal, P., Vitery, S., et al. (2010) Fractal Generalization of Preneoplastic and Cancerous Cells of the Cervical Squamous Epithelium of Clinical Application. Revista de la Facultad de Medicina, 18, 173-181. 
[22] Prieto, S., Rodríguez, J., Correa, C. and Soracipa, Y. (2014) Diagnosis of Cervical Cells Based on Fractal and Euclidian Geometrical Measurements: Intrinsic Geometric Cellular Organization. BMC Medical Physics, 14, 2. https://doi.org/10.1186/1756-6649-14-2

[23] Velásquez, J., Prieto, S., Catalina, C., Dominguez, D., Cardona, D.M. and Melo, M. (2015) Geometrical Nuclear Diagnosis and Total Paths of Cervical Cell Evolution from Normality to Cancer. Journal of Cancer Research and Therapeutics, 11, 98-104. https://doi.org/10.4103/0973-1482.148704

[24] Stehlík, M., Mrkvička, T., Filus, J. and Filus, L. (2012) Recent Developments on Testing in Cancer Risk: A Fractal and Stochastic Geometry. Journal of Reliability and Statistical Studies, 5, 83-95.

[25] Rodríguez, J., Mariño, M., Avilán, N. and Echeverri, D. (2002) Fractal Measurements of Coronary Arteries in an Experimental Model of Restenosis. Revista Colombiana de Cardiología, 10, 65-62.

[26] Rodríguez, J., Prieto, S., Correa, C., Bernal, P., Álvarez, L., Forero, G., et al. (2012) Fractal Diagnosis of Left Heart Ventriculograms: Fractal Geometry of Ventriculogram during Cardiac Dynamics. Revista Colombiana de Cardiología, 19, 18-24.

[27] Rodríguez, J., Prieto, S., Ortiz, L., Ronderos, M. and Correa, C. (2010) Mathematical Diagnosis of Pediatric Echocardiograms with Fractal Dimension Measures Evaluated through Intrinsic Mathematical Harmony. Revista Colombiana de Cardiología, 17, 79-86.

[28] Rodríguez, J. (2011) Mathematical Law of Chaotic Cardiac Dynamic: Predictions of Clinic Application. Journal of Medicine and Medical Sciences, 2, 1050-1059.

[29] Correa, C., Rodríguez, J., Prieto, S., Álvarez, L., Ospino, B., Munévar, A., et al. (2012) Geometric Diagnosis of Erythrocyte Morphophysiology: Geometric Diagnosis of Erythrocyte. Journal of Medicine and Medical Sciences, 3, 715-720.

[30] Rodríguez, J., Prieto, S., Correa, C., Soracipa, Y., Polo, F., Pinilla, L., et al. (2014) Fractal and Euclidean Geometric Diagnostic Methodology of Cervical Cells. Iatreia, 27, 5-13.

[31] Deogratius, A., Sarikiaeli, E., Wabinga, H. and Walter, F. (2015) Symptomatic Presentation with Cervical Cancer in Uganda: A Qualitative Study Assessing the Pathways to Diagnosis in a Low-Income Country. BMC Women's Health, 15, 15. https://doi.org/10.1186/s12905-015-0167-4

[32] Tolman, R. (1979) Principles of Statistical Mechanics. 2th Edition, Dover Publications, New York.

[33] Crutchfield, J., Farmer, D., Packard, N. and Shaw, R. (1990) Caos. In: Orden y Caos, Scientific American, Prensa Científica S.A, 78-90.

[34] Rodríguez, J., Prieto, S., Domínguez, D., Melo, M., Mendoza, F., Correa, C., et al. (2013) Mathematical-Physical Prediction of Cardiac Dynamics using the Proportional Entropy of Dynamic Systems. Journal of Medicine and Medical Sciences, 4 , 370-381.

[35] Rodríguez, J., Prieto, S., Dominguez, D., Correa, C., Melo, M., Pardo, J., et al. (2014) Application of the Chaotic Power Law to Cardiac Dynamics in Patients with Arrhythmias. Revista de la Facultad de Medicina, 62, 539-546. https://doi.org/10.15446/revfacmed.v62n4.43444

[36] Rodríguez, V.J. (2010) Method for the Prediction of the Temporal Dynamics of Malaria in the Municipalities of Colombia. The Revista Panamericana de Salud Pública, 27, 211-218.

[37] Rodríguez, J., Prieto, S., Correa, C., Pérez, C., Mora, J., Bravo, J., et al. (2013) Pre- 
dictions of CD4 Lymphocytes' Count in HIV Patients from Complete Blood Count. BMC Medical Physics, 13, 3. https://doi.org/10.1186/1756-6649-13-3

[38] Rodríguez, J. (2008) Binding to Class II HLA Theory: Probability, Combinatory and Entropy Applied to Peptide Sequences. Inmunología, 27, 151-166. https://doi.org/10.1016/S0213-9626(08)70064-7

[39] Rodríguez, J. (2015) Dynamical Systems Applied to Dynamic Variables of Patients from the Intensive Care Unit (ICU) Physical and Mathematical Mortality Predictions on ICU. Journal of Medicine and Medical Sciences, 6, 209-220. 